\title{
Interpretation for the Pressure and Temperature Signals of Injection Molding Process
}

\author{
Yugang Huang ${ }^{1,2}$ \& Suhua Zhao ${ }^{2}$ \\ ${ }^{1}$ State Key Laboratory of Powder Metallurgy, Central South University, Changsha, China \\ ${ }^{2}$ Packaging and Materials Engineering School, Hunan University of Technology, Zhuzhou, China \\ Correspondence: Yugang Huang, Packaging and Printing Lab Building, Hunan University of Technology, \\ Zhuzhou, China. E-mail: hyg126com@126.com
}

Received: March 8, 2013 Accepted: April 7, 2013 Online Published: April 15, 2013

doi:10.5539/jmsr.v2n3p43 URL: http://dx.doi.org/10.5539/jmsr.v2n3p43

\begin{abstract}
An apparatus was developed to acquire temperature and pressure data from the injection molding process. There were three collecting points along the flow path which were allocated at the entrance to the nozzle, near the cavity gate and at the cavity end. Values and plots of temperature and pressure signals were interpreted. Firstly, each acquired signal was detailed introduced, and the characteristic points and segments of the signal plot were explained. Furthermore, comparison of process information which was introduced by one single was made among all of the acquired signals. The practical analysis shows that the pressure signal near the cavity gate is the most effective to describe the status of the sample melt during the injection molding process. But it has the significant delay of indicating the beginning of the cavity filling. With the explanation of signals, the injection molding experiments on the self-developed apparatus can be used to study the processing parameters of sample material.
\end{abstract}

Keywords: pressure signal, temperature signal, injection molding, process information

\section{Introduction}

As the most important shaping method for plastics, the injection molding attracted many researchers' attention in the field of materials processing (Michaeli et al., 2012; Moritzer et al., 2012; Mulyana et al., 2012). During the study on the optimization of processing parameters (Rudolph et al., 2011; Lu et al., 2012), the process simulation (Thornagel \& Florez, 2012), experimental validation (Simacek et al., 2012), quality control of molded products (Woll \& Cooper, 1997), and development of new injection process (Chang \& Yeh, 2012; Lee et al., 2012; Peng et al., 2012), the temperature and pressure signals were essential data for the flow analysis of injection molding.

Dominick et al. (2000) introduced the typical cavity pressure trace for the process control of injection molding. In their introduction the cavity pressure signal plot was divided into four segments, i.e. filling phase, melt compression phase, holding phase and additional cooling phase. Papathanasiou and Kamal (1993) studied the cavity pressure during the filling phase by numerical results. The effect of mold geometry on pressure-time profiles and the effects of ram velocity and melt temperature on the pressure drop in the cavity were presented. Woll and Cooper $(1996,1997)$ monitored the quality of injection molded parts using analysis of complete data patterns rather than discrete data or peak values. According to the process of the injection molding, including mold filling, mold packing, part cooling and mold opening, they characterized a typical cavity pressure profile with the features such as an initial rise, a peak value, a transitional region, a packing pressure plateau and the pressure decay. Zhang and Alexandera (2008) interpreted two cavity pressures via artificial neural networks for process condition monitoring and fault diagnosis. All these investigations focused mainly on the cavity pressure signal which was not convenient for data acquisition during traditional injection molding manufactory. To acknowledge the injection molding process thoroughly and comprehensively, other conditions such as injection pressure, cavity temperature and barrel temperature should be also understood.

An injection molding apparatus has been built in our laboratory recently. With this self-developed apparatus, molded parts and process signals can be acquired after injection molding experiments. In order to analyze and optimize of the injection molding process for a test sample, the process signals from the flow field should be comprehensively understood. 
Six signals collected on the self-developed apparatus were interpreted in this work, including the melt pressure/temperature near the cavity gate, the melt pressure/temperature at the entrance to the nozzle, and the melt pressure/temperature at the cavity end. After individual introduction of them, the relationship among these signals was considered.

\section{Procedure: Pressure and Temperature Data Acquisition}

The shape and dimensions of molded part was shown in Figure 1(a). The part is a cuboid used as the sample bar for plastic bending performance test. There are three points for signal acquisition, as can be seen in Figure 1 . One of them is located near the cavity gate, named "Point GT". Another is called "Point END" at the end of the cavity. "Point $I N J$ ' is in the barrel and near the entrance to the nozzle. A combined pressure and temperature sensor at each point collects two signals of the flow state.

All of the experiments were performed with a common polymer of polypropylene (PP) T30S (produced by Sinopec Maoming Co., China, with MFR $3.0 \mathrm{~g} / 10 \mathrm{~min}$, at $230^{\circ} \mathrm{C} / 2.16 \mathrm{~kg}$ ). It has a melt flow index of $3.0 \mathrm{~g} / 10$ $\min \left(\right.$ at $230{ }^{\circ} \mathrm{C}$ and $2.16 \mathrm{~kg}$ ) and a mass-average molecular weight of $348,000 \mathrm{~g} / \mathrm{mol}$.

The default conditions of injection molding experiments are shown in Table 1. In addition, the diameter of the barrel reservoir is $25 \mathrm{~mm}$.

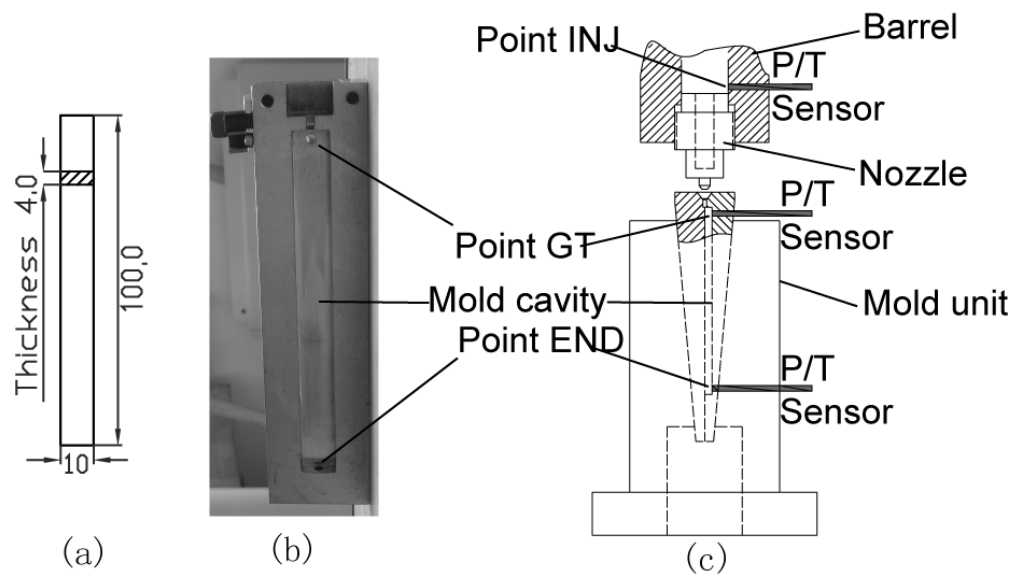

Figure 1. Measurement locations: (a) shape and dimension of the molded part, (b) photo of the mold board, (c) schematic of the measurement distribution

Table 1. Default values of test conditions

\begin{tabular}{ll}
\hline Test conditions & Value \\
\hline Melt temperature $/{ }^{\circ} \mathrm{C}$ & 180 \\
Mold temperature $/{ }^{\circ} \mathrm{C}$ & 20 \\
Injection speed $/ \mathrm{mm} / \mathrm{s}$ & 8 \\
Injection distance $/ \mathrm{mm}$ & 18 \\
Packing speed $/ \mu \mathrm{m} / \mathrm{s}$ & 50 \\
Packing time $/ \mathrm{s}$ & 10 \\
\hline
\end{tabular}

The pressure and temperature signals were recorded by the combined pressure and temperature sensors (Kistler Instrument AG, type 6189A, Winterthur, Switzerland). Data acquisition was performed on a Kistler CoMo Injection (Kistler Instrument AG, type 2869B, Winterthur, Switzerland). Figure 2 shows the original display of the six synchronous signals on the interface of the data acquisition system. 


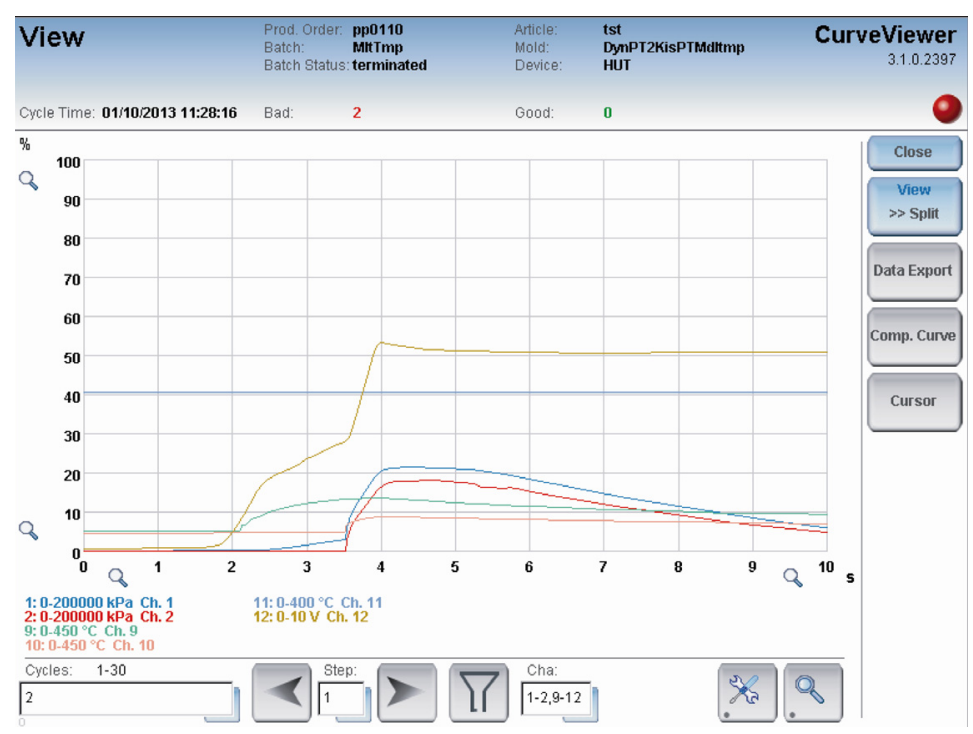

Figure 2. View of the measurement data

\section{Results}

\subsection{Pressure Data near the Cavity Gate}

As shown in Figure 3, the valid signal of the cavity pressure near the gate $\left(P_{g t}\right)$ began at $2.2 \mathrm{~s}$ and ended at $6.6 \mathrm{~s}$. After the time of $6.6 \mathrm{~s}$, we believe, the surface layer of molded part in the cavity has solidified so that the pressure decline measured by the sensor slows down. The valid part of the pressure $P_{g t}$ can be described as four segments divided by three inflection points. Four segments correspond to filling, compression, holding and cooling phase of the injection molding process. And three inflection points represent the peak pressure, the end of filling and the closure of the gate. From the signal shown in Figure 3, it can be learned that the filling time under current test conditions is about 3.2-2.2=1.0 s. And the holding time should be no less than the gate seal time of $5.2-3.5=1.7 \mathrm{~s}$. Moreover, the pressure drop in the cavity is $\sim 5 \mathrm{MPa}$. The clamping force should be larger than the peak pressure of $12 \mathrm{MPa}$.

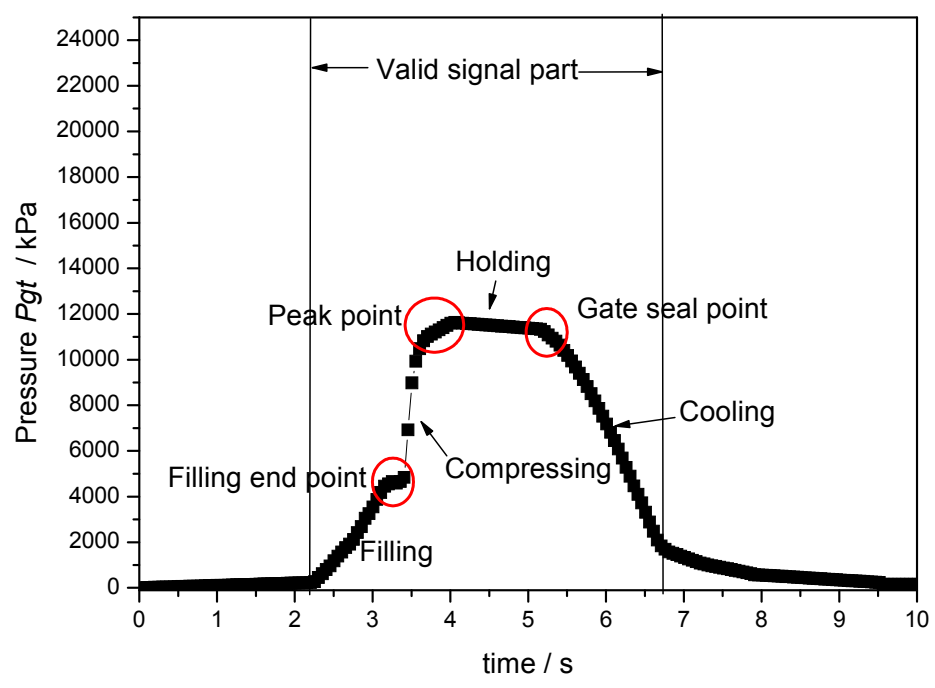

Figure 3. Typical pressure signal near the cavity gate

\subsection{Temperature Data near the Cavity Gate}

Figure 4 shows that the temperature near the cavity gate $\left(T_{g t}\right)$ begins to increase at the time of $2.0 \mathrm{~s}$. It is $0.2 \mathrm{~s}$ earlier than that of the $P_{g t}$ starting point. During this 0.2 second, we believe, the melt entering the cavity is too 
little to build the pressure which could be sensed by the pressure transducer. So we conclude that the temperature $T_{g t}$ signal is more sensitive for the start of cavity filling than pressure $P_{g t}$ signal. On the contrary, for the sake of thermal inertia the temperature $T_{g t}$ signal is not good as the pressure $P_{g t}$ signal for indicating the change of decrease. As can be seen from Figure 4, the decline segment of temperature $T_{g t}$ signal is very flat.

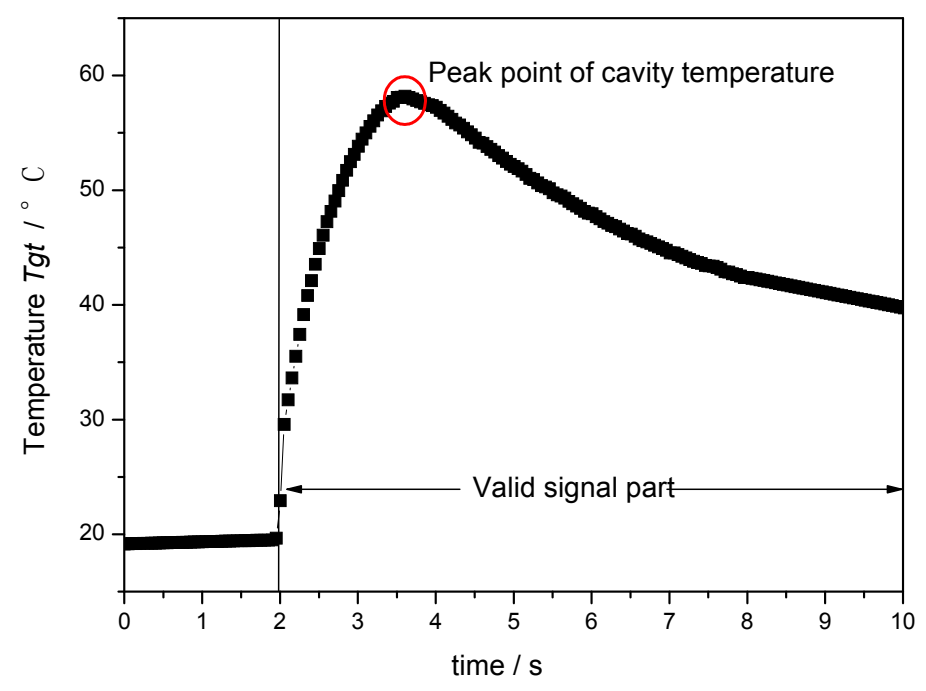

Figure 4. Temperature signal near the cavity gate

\subsection{Injection Pressure Data at the Entrance to the Nozzle}

From the pressure signal at the entrance to the nozzle $\left(P_{i n j}\right)$, as shown in Figure 5, the operating procedure of the injection molding can be found out. Ahead of the filling, there is an initial rise which indicates the compaction of the melt sample in the barrel reservoir. The front half of the filling segment corresponds to the filling of the runner system. The latter half indicates the filling of the mold cavity. The inflection point between them represents the melt breaking through the cavity gate. If the injection distance (i.e. shot size) increases to $22 \mathrm{~mm}$, as can be seen from Figure 5(b), another steep rise segment is added to the filling stage. It indicates that the excessive filling leads to the sudden compaction of the molded part in the cavity. The turning point at the front end of the added segment introduces us the threshold injection pressure for the cavity just filled. Normally the peak value of injection pressure should be slightly less than the threshold, which avoids the excessive filling as shown in Figure 5(a). The peak point of the pressure $P_{i n j}$ provides the injection pressure requirement is $\sim 23 \mathrm{MPa}$. The transitional segment connects the packing plateau segment to the peak point. When the packing time runs out, the pressure $P_{i n j}$ declines rapidly as shown by the last segment in Figure 5(a).

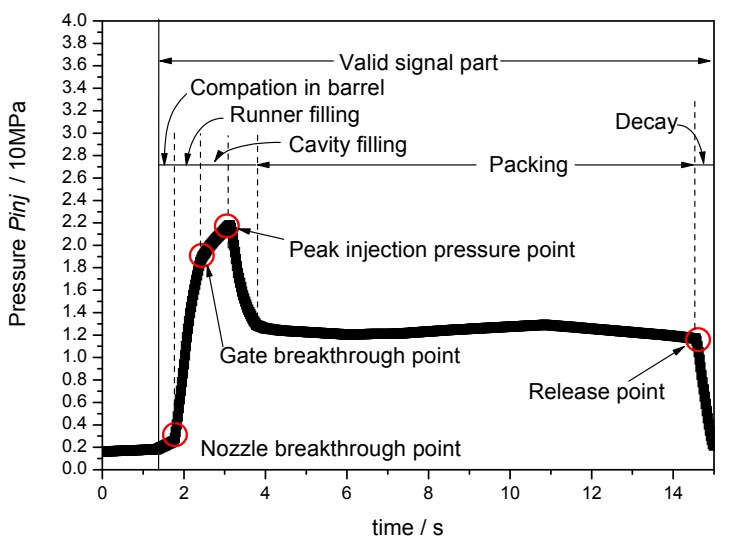

(a)

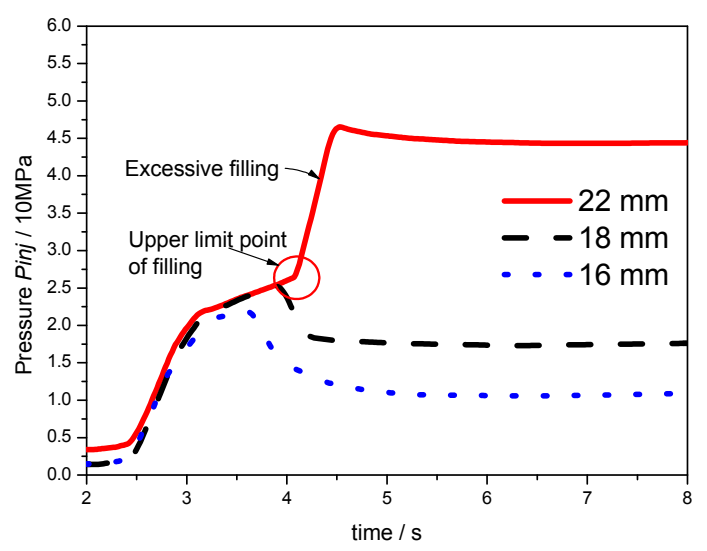

(b)

Figure 5. (a) Pressure signal at the entrance to the nozzle; (b) signal expansion by increasing the injection distance 


\subsection{Melt Temperature Data at the Entrance to the Nozzle}

The melt temperature at the entrance to the nozzle $\left(T_{i n j}\right)$, as shown in Figure 6, remains constant during the whole injection molding cycle.

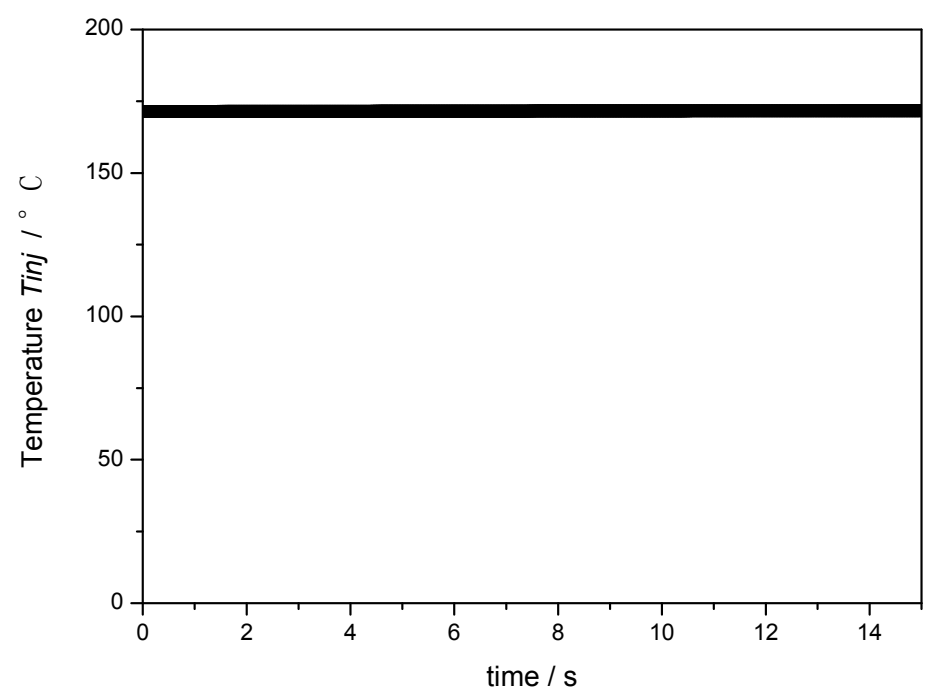

Figure 6. Temperature signal at the entrance to the nozzle

\subsection{Pressure Data at the Cavity End}

The pressure at the cavity end $\left(P_{\text {end }}\right)$ increases immediately to the peak point, as can be seen from Figure 7 , which means that the compaction of the molded part occurs as soon as the melt flow arrives at the end of the cavity. Before the gate seals, the pressure $P_{\text {end }}$ stays at the holding plateau. Then it decays to the idle pressure. The valid signal of $P_{\text {end }}$ starts at $3.5 \mathrm{~s}$, and it ends at $6.8 \mathrm{~s}$. We believe that the holding time greater than $3.3 \mathrm{~s}$ $(6.8-3.5=3.3)$ is enough for packing.

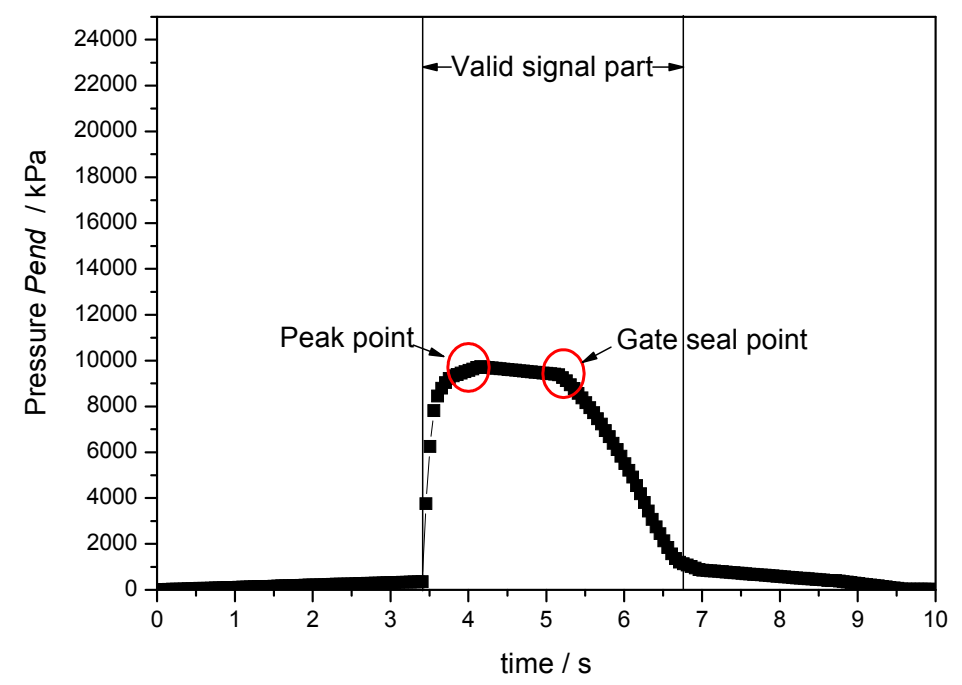

Figure 7. Pressure signal at the cavity end

\subsection{Temperature Data at the Cavity End}

Similar to the $P_{\text {end }}$, the melt temperature at the cavity end $\left(T_{\text {end }}\right)$ increases immediately to the peak point, as shown in Figure 8. 


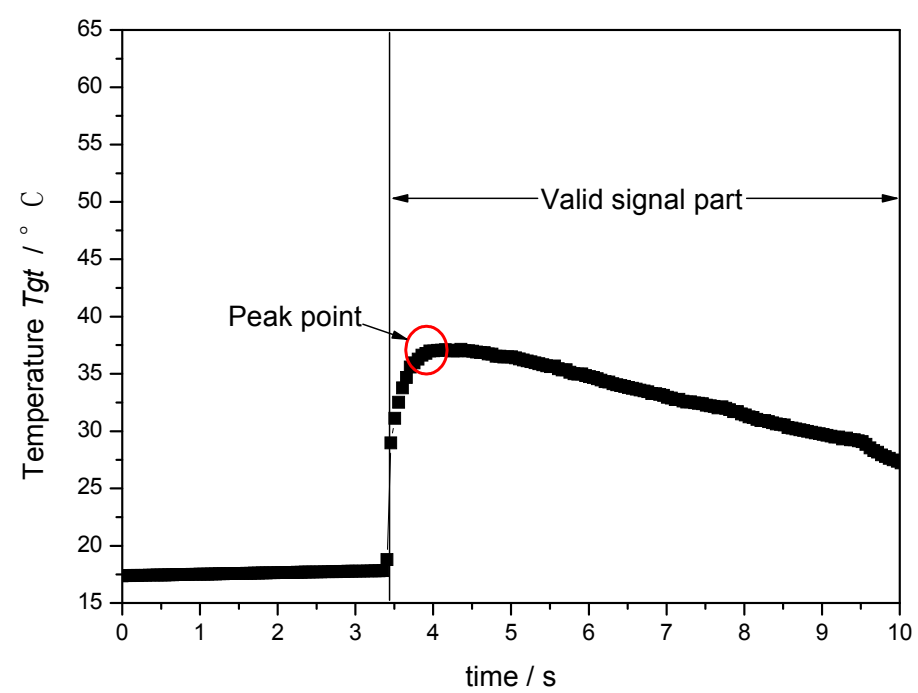

Figure 8 . Temperature signal at the cavity end

\section{Discussion}

As all of the pressure and temperature signals were plotted together for comparison in Figure 9, in-depth findings can be got by the comprehensive analysis. Injection pressure $P_{i n j}$ is the first one to reflect the beginning of the injection molding process. The temperature $T_{g t}$ denotes the cavity filling earlier than the pressure $P_{g t}$. The temperature $T_{g t}$, the pressure $P_{\text {end }}$ and the temperature $T_{\text {end }}$ are agreed at the end of filling. For the gate seal and the end time of holding both the pressure $P_{g t}$ and the pressure $P_{\text {end }}$ have the signal characteristic of inflection point, and the others have not. On the other hand, with comparison of dependent variable, we find significant differences among these signals. Even as the melt stops flowing, for example in the holding stage, the values of the pressure signals do not agree with each other. This means the elastic behaviour of the sample melt has significant influence on the injection molding process.

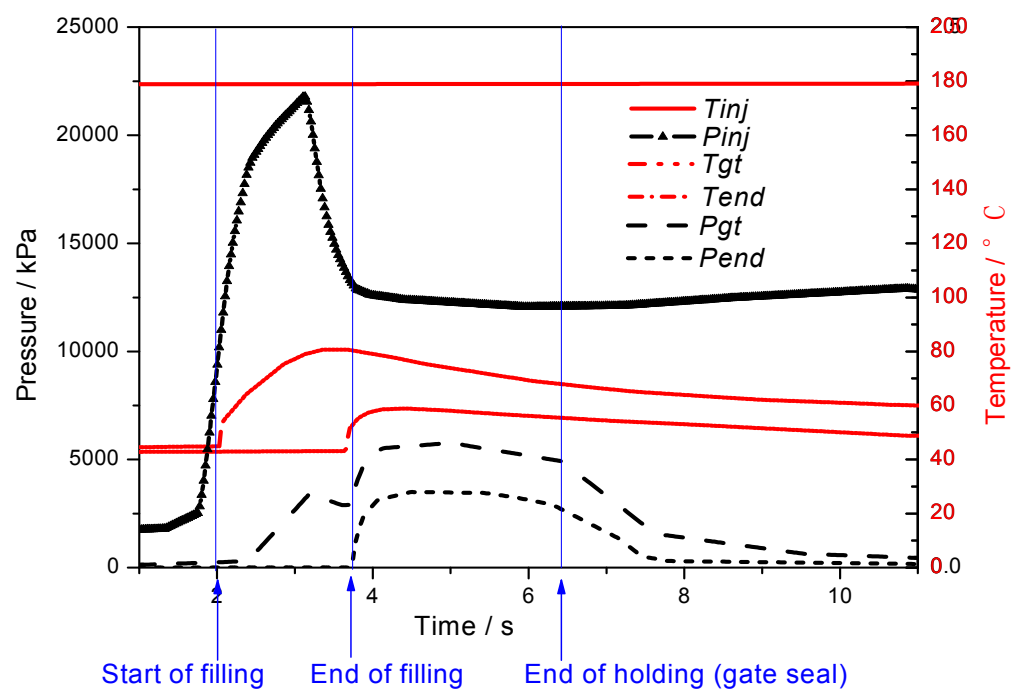

Figure 9. Comparison of signals

\section{Conclusion}

The injection pressure $P_{i n j}$ introduces the melt compressing in the barrel reservoir and the peak value of the injection pressure. Because its signal acquisition position is far away from the molded part what is usually concerned, with the influence of gating system much other information of the pressure $P_{i n j}$ signal is not 
significant for study on processing status. Especially it can't introduce anything about the molded part after the filling stage.

The melt temperature $T_{i n j}$ at the entrance to the nozzle shows nothing about the injection molding process.

The pressure $P_{g t}$ near the cavity gate clearly expresses the end of filling and the end of packing. It denotes a delayed increase characteristic of the beginning of the cavity filling. Nevertheless, the cavity pressure $P_{g t}$ is the most effective signal for process characterization relatively.

The temperature $T_{g t}$ near the cavity gate exactly denotes the beginning of the cavity filling.

The pressure $P_{\text {end }}$ at the cavity end also introduces the end of filling.

The temperature $T_{\text {end }}$ at the cavity end denotes the arriving of the melt front at the end of the cavity.

\section{Acknowledgements}

The authors gratefully acknowledge financial support by the National Natural Science Foundation of China (Grant No. 10972076), the science and technology plan project of Hunan province (Grant No. 2011TT2028), and the project of Central South University (Grant No. 1343-74334000010).

\section{References}

Chang, M. T., \& Yeh, C. H. (2012). An innovative manufacturing process for bamboo injection molding by using TRIZ and Taguchi method. Journal of the Chinese Institute of Industrial Engineers, 29(7), 454-465. http://dx.doi.org/10.1080/10170669.2012.727477

Dominick, V. R., Donald, V. R., \& Marlene, G. R. (2000). Injection Molding Handbook. Boston: Kluwier Academic Publishers.

Lee, J., Turng, L. S., Dougherty, E., \& Gorton, P. (2012). A novel foam injection molding process using gas-laden pellets. 70th Annual Technical Conference of the Society of Plastics Engineers 2012, ANTEC 2012, April 2, 2012 - April 4, 2012, Orlando, FL, United states, Society of Plastics Engineers.

Lu, N. Y., Gong, G. X., Yang, Y., \& Lu, J. H. (2012). Multi-objective process parameter optimization for energy saving in injection molding process. Journal of Zhejiang University: Science A, 13(5), 382-394. http://dx.doi.org/10.1631/jzus.A1100250

Michaeli, W., Hopmann, C., \& Fragner, J. (2012). Analysis of the injection moulding process of soft magnetic plastics compounds. 2012 2nd International Electric Drives Production Conference, EDPC 2012, October 15, 2012 - October 18, 2012, Nuremberg, Germany, IEEE Computer Society.

Moritzer, E., Schafers, M., \& Plugge, T. (2012). Two-Stage-GITBlow: a process for complex and multi-functional injection molding parts. Zeitschrift Kunststofftechnik/Journal of Plastics Technology, (1), 23-52.

Mulyana, R., Cabrera, E., Castro, J. M., Lee, L. J., \& Min, Y. (2012). Injection molding of water containing thermoplastic polyolefin. International Polymer Processing, 27(1), 9-17. http://dx.doi.org/10.3139/217.2494

Papathanasiou, T. D., \& Kamal, M. R. (1993). Filling of a Complex-Shaped Mold with a Viscoelastic Polymer. Part I: The Mathematical Model. Polymer Engineering and Science, 33(7), 400-409. http://dx.doi.org/10.1002/pen.760330705

Peng, J., Turng, L.S., \& Osswald, T. A. (2012). A new microcellular injection molding process for polycarbonate using water as the physical blowing agent. Polymer Engineering and Science, 52(7), 1464-1473. http://dx.doi.org/10.1002/pen.23092

Rudolph, N., Pich, F., \& Osswald, T. (2011). Effects of temperature and pressure on viscosity during injection molding. 69th Annual Technical Conference of the Society of Plastics Engineers 2011, ANTEC 2011, May 1, 2011 - May 5, 2011, Boston, MA, United states, Society of Plastics Engineers.

Simacek, P., Eksik, O., Heider, D., Gillespie Jr, J. W., \& Advani, S. (2012). Experimental validation of post-filling flow in vacuum assisted resin transfer molding processes. Composites Part A: Applied Science and Manufacturing, 43(3), 370-380.

Thornagel, M., \& Florez, L. (2012). Process simulation of rubber injection moulding: Effects of inserts on the heat flux and the article quality. KGK Kautschuk Gummi Kunststoffe, 65(5), 49-54. 
Woll, S. L. B., \& Cooper, D. J. (1996). Online Pattern-Based Part Quality Monitoring of the Injection Molding Process. Polymer Engineering and Science, 36(11), 1477-1488. http://dx.doi.org/10.1002/pen.10542

Woll, S. L. B., \& Cooper, D. J. (1997). Pattern-Based Closed-Loop Quality Control for the Injection Molding Process. Polymer Engineering and Science, 37(5), 801-812. http://dx.doi.org/10.1002/pen.11723

Zhang, J., \& Alexandera, S. M. (2008). Fault diagnosis in injection moulding via cavity pressure signals. International Journal of Production Research, 46(22), 6499-6512. http://dx.doi.org/10.1080/00207540701429918 